América sin Nombre, n. ${ }^{\circ} 24$ (2020): 13-22

DOI 10.14198/AMESN.2020.24-2.01

ISSN: 1577.3442 / eISSN: 1989-9831

Fecha de recepción: 06/02/2019

Fecha de aceptación: 20/03/2019
Modo de citación de este artículo:

Correa Lust, Constanza Inés. "Mario Benedetti y el ensayo: la práctica discursiva de un intelectual comprometido"". La nueva novela latinoamericana sin límites. Lise Segas y Félix Terrones (coordinadores). América sin Nombre, 24 (2020): 13-22, DOI: 10.14198/AMESN.2020.24-2.01

Link para este artículo: http://dx.doi.org/10.14198/AMESN.2020.24-2.01

\title{
«Mario Benedetti y el ensayo: la práctica discursiva de un intelectual comprometido»
}

\section{«Mario Benedetti and the essay: the discursive practice of a committed intellectual»}

\author{
Constanza Inés Correa Lust* \\ Universidad Nacional de Cuyo (Argentina)
}

\begin{abstract}
Resumen
El ensayo, en Latinoamérica, se presenta como discurso textual específico que permite el debate crítico sobre la cultura y las distintas funciones socio-políticas de la literatura. Este género se presenta como un campo discursivo en el cual los intelectuales intervienen asiduamente $\mathrm{y}$, ya en la segunda mitad del siglo xx, representa la forma discursiva predominante (aunque no excluyente) entre los «intelectuales comprometidos». La ensaýstica de un intelectual uruguayo de amplia repercusión y difusión como Mario Benedetti, nos ofrece la oportunidad para analizar cómo este género se presenta como una práctica discursiva privilegiada para el ejercicio de la función enunciativa de quienes defendieron el compromiso de la literatura como un modo de lucha contra el neocolonialismo. Nos proponemos entonces analizar, mediante el análisis del discurso, cómo la elección de un género específico como el ensayo, tiene una función pragmática que responde a una manera particular de concebir el ejercicio intelectual.
\end{abstract}

Palabras claves: Benedetti, ensayo, intelectual, compromiso, práctica discursiva.

\section{Abstract}

The essay, in Latin America, is presented as a specific textual discorse that allows critical debate about the culture and the different socio-political functions of literature. This genre is presented as a discursive field in which intellectuals intervene assiduosly; during the second half of the 20th century, it represents the predominant (though not excluding) discursive form among committed intellectuals.

The essay of a Uruguayan intellectual of wide repercussion and diffusion as Mario Benedetti, offers us the opportunity to analyze how this genre appears as a privileged discursive practice for the exercise of the enunciative function of those who defended the commitment of literature as a way of fight against neocolonialism. That's why, we propose to analyze, though discourse analysis, how the choice of a specific genre such as the essay has a pragmatic function that responds to a particular way of conceiving the intellectual exercise.

Keywords: Benedetti, essay, intellectual, commitment, discursive practice.

* Profesora de Grado Universitario en Lengua y Literatura, egresada de la Facultad de Filosofía y Letras de la Universidad Nacional de Cuyo. Actualmente se encuentra realizando su último año del Doctorado en Letras en la misma casa de estudios, siendo para ello becada por el CONICET. Se especializa en Literatura Hispanoamericana y su tesis doctoral aborda la relación entre ensayo y compromiso en la obra del uruguayo Mario Benedetti. A lo largo de su formación académica ha realizado estancias de estudio en México y Uruguay. Al mismo tiempo, ha participado de diferentes disertaciones en Montevideo, Madrid y diversas casas de estudio de la Argentina. 


\section{Introducción}

Mario Benedetti ha sido uno de los escritores más prolíficos y polémicos entre el grupo de escritores uruguayos que se conoció como 'Generación del 45'. Como escritor incursionó incansablemente en todos los géneros literarios; participando activamente de los debates ideológicos del país y del continente. Sin embargo, todavía hoy, el ensayo y, en general, la «literatura de ideas» del autor - aquella en la cual hace explícitos sus posicionamientos y opciones estéticoéticas - es quizá el ámbito menos abordado de su producción.

El compromiso intelectual que embanderó el escritor uruguayo desde su filiación con las ideas de la Revolución Cubana - y que lo acompañará durante su exilio en Cuba y España y hasta el final de sus días- tiene su correspondiente codificación en prácticas discursivas concretas, que permiten el debate crítico sobre la cultura y las ideologías; y sobre las distintas concepciones que la literatura ha tenido respecto de su función socio-política en nuestro continente. Es en esta práctica discursiva en donde, en palabras de Larre Borges, se determinan para Benedetti "las coordenadas de una literatura diseñada en el inconformismo, la crítica social, la desacralización del arte y la apuesta por la comunicación respecto a sus lectores» (Larre Borges 47).

\section{El campo intelectual}

En términos generales, es necesario partir del hecho de que se está hablando de un campo intelectual que, en tanto ámbito discursivo, tiene sus características propias que se ven reflejadas en los discursos que lo conforman. Carlos Altamirano describe este fenómeno del siguiente modo:

El campo intelectual (...) es a la vez un espacio de competencia y de disputa. ¿Cuál es el objeto de estas querellas? La definición de la cultura legítima. Una lucha que enfrenta a quienes ocupan diferentes posiciones en ese espacio. (...) Aprehender sincrónicamente el campo es captarlo como un sistema de posiciones (...) no todos tienen el mismo poder para definir la cultura legítima. Un poder que depende del capital simbólico, (o prestigio, autoridad, reconocimiento social, ligado a cada posición)» (Altamirano 97).

Sin embargo, y antes de avanzar más en los procesos de legitimación que erigen a los intelectuales en tanto tales, quizá sea conveniente hacer un breve acercamiento a la categoría de «intelectuales» en sí misma. Para ello consideramos conveniente remitirnos nuevamente a Altamirano, ya que él, en su libro Intelectuales, realiza un pormenorizado relevamiento de los distintos matices que fue tomando esta definición. Dice el autor:

El rótulo de intelectual (...) no es una clasificación socio-profesional, no remite a una ocupación determinada en algún sector del saber o de la creación literaria o artística, sino al comportamiento de tales personas en relación con la esfera pública, es decir, el desempeño de un papel en los debates de la ciudad» (11).

Los intelectuales han representado a lo largo de la historia, según Altamirano, una especie particular de autoridad, de "tribunal de hombres de cultura» que interfiere en el campo cultural bajo la presunción de que esa autoridad se justifica por un dominio de los bienes pertenecientes a la cultura legítima (y aquí se expresa en términos de Bourdieu). Al mismo tiempo, este dominio supone un derecho a desempeñar los roles de críticos sociales y moralistas públicos, dotando a su interacción en la sociedad de un carácter ético, en cumplimiento de una misión particular.

Claudia Gilman, hablando ya particularmente de los intelectuales de la segunda mitad del siglo xx en Latinoamérica, parece coincidir con estas apreciaciones cuando dice que «Desde este lugar simbólico del intelectual como conciencia crítica, muchos de los escritores del período fundaron su legitimidad» (Gilman 73).

También Bauman, al plantear la categoría de los intelectuales en tanto «legisladores», habla en similares términos, diciendo que son

(...) figuras públicas que consideran como su responsabilidad moral y su derecho colectivo intervenir directamente en el sistema político mediante su influencia sobre las mentes de la nación y la configuración de las acciones de sus dirigentes políticos» (Bauman 7).

Por lo hasta aquí expuesto, se puede apreciar que una de las principales cuestiones en torno a la definición de este grupo de "hombres de ideas» (que por otra parte, suele ser propenso a las autodefiniciones) radica en la fuente de esa autoridad que se funda como reguladora de su relación con los otros campos de la sociedad. Al mismo tiempo, eso que se entiende por autoridad, visto desde un punto gramsciano, no es otra cosa que la hegemonía, es 
decir, "una dirección intelectual y moral de una clase sobre otra» (ctd. en Altamirano 75). Los intelectuales resultan, de este modo, "funcionarios de la hegemonía (...) élites culturales [con] un lugar medular en la estrategia del cambio social» (Altamirano 75).

Vista ya como un derecho adquirido, como misión propia o como responsabilidad inherente, lo cierto es que su influencia sobre la opinión pública, así como la visibilidad que hace de ellos mismos «intelectuales» y no otra cosa, no es contingente ni azarosa, sino que deviene de un proceso de construcción. Es mediante un proceso de legitimación que estos escritores asumen su rol; mediante la ejecución de una práctica discursiva se va generando un campo de poder. Elvira Blanco lo explica de la siguiente forma:

La lucha por el poder es una lucha por el dominio de los discursos y una de las vías de conquistas de ese poder, es el control de la producción simbólica, a partir de la desarticulación del discurso oficial. El poder letrado se legitima en editoriales, revistas, críticos, académicos, y todo el complejo sistema de autoridad cultural de la sociedad, que con el tiempo pasa a ejercer la canonización de esos discursos y de los emisores. (...) de esta forma, la práctica discursiva se transforma en un proyecto que va oficializándose en la medida que al otro se le restringe el espacio de acción en lo cultural y en lo político (85).

Ahora bien, como ya se dijo anteriormente, la figura del intelectual adquiere, en la segunda mitad del siglo $\mathrm{xx}$ latinoamericano, características especiales en cuanto a su desempeño, así como también condiciones específicas que modificaron el proceso de legitimación de estos grupos.

\section{El intelectual comprometido}

El advenimiento de los sesenta y la politización de la vida cultural latinoamericana insertó nuevos parámetros en los procesos de legitimación de quienes se consideraban a sí mismos intelectuales. La Revolución Cubana de 1959 funcionó en este sentido como un hito que reagrupó a la mayoría de los intelectuales en la opción política de la izquierda, e instaló nuevas reglas de juego que pusieron en el centro una cuestión central: la del compromiso del intelectual. En este sentido, sostiene Claudia Gilman que, en aquellos años,
La posibilidad del deslizamiento de la obra a la vida era inescindible de la noción de compromiso y, por lo tanto, la inclusión de la conducta y la autovigilancia como parte del pacto del intelectual con la sociedad era un curso posible; la actitud del escritor-intelectual fue el parámetro con el que se midió la legitimidad político-ideológica de su práctica poética (149).

De las palabras de la autora se deprende que este compromiso era un tópico que se traducía en una práctica social que marcó a toda una generación, y que estaba profundamente influenciado por las ideas que Jean Paul Sartre volcó, sobre todo, en su obra ¿Qué es la literatura? La idea de un escritor que no puede sustraerse de la realidad que lo rodea a la hora de escribir no solo repercute en lo que estos intelectuales escriben, sino también en la manera en que se relacionan con sus pares y con el mundo en general:

(...) ya que el escritor no tiene modo alguno de evadirse, queremos que se abrace estrechamente con su época. Es su única oportunidad. Su época está hecha para él y él está hecha para ella. Aunque nos mantuviéramos mudos y quietos, como una piedra, nuestra misma pasividad sería una acción. Quien consagrara su vida a hacer novelas sobre los hititas tomaría posición por esta abstención misma. El escritor tiene una situación en su época. Cada palabra suya repercute (Sartre 10).

El rol del intelectual en la segunda mitad del siglo $\mathrm{xx}$ latinoamericano estaba entonces en estrecha relación con el campo político. La literatura se volvía también un campo de batalla en el que los escritores devenían primero en intelectuales y luego en guías de un público lector que se había afianzado con la ayuda del boom editorial propio de la época. Los escritores estaban interpelados por ese mismo público al que constantemente se sentían en el compromiso de conducir ideológicamente, instalando a través de la polémica la batalla contra todas aquellas ideas que, fuera del texto pero desde la misma lógica del discurso, impedían que se instalara la revolución en la sociedad. Gilman lo explica en el siguiente párrafo:

La noción de intelectual comprometido conservaba la alusión a la pertenencia profesional y se refería a los intelectuales en tanto grupo de sujetos parcialmente especializados en torno a un tipo de saber. Pero, paradójicamente, también los convertía en portavoces de una conciencia humanista y universal que se desplegaba más allá de las fronteras y de las nacionalidades. 
La doctrina del compromiso aseguraba a los intelectuales una participación en la política sin abandonar el propio campo, al definir una tarea intelectual como un trabajo siempre, y de suyo, político (72).

Cabe en este punto preguntarse qué se entiende por compromiso. Iván Ulloa Bustinza sostiene al respecto, y en consonancia con las dificultades conceptuales previamente comentadas, que

(...) es imposible una definición a priori del concepto de compromiso. Para que una determinada obra se considere comprometida, no basta con que el pensamiento de la misma se adhiera al pensamiento oficial o que se inscriba sin más en un movimiento revolucionario o de oposición. El compromiso, antes bien, se establece entre el sujeto creador y su época, más allá de facciones ideológicas opuestas (Ulloa Bustinza 29).

Como es de suponer, lo escurridizo del concepto del compromiso supuso toda una nueva serie de debates dentro del campo cultural, en aras de poder determinar cuáles eran los parámetros para medir si un intelectual era comprometido o no y para asignarle la consecuente legitimación que para estos años significaba dicho calificativo. Es decir, se recurre nuevamente a la construcción discursiva de un escenario simbólico que otorgue autoridad a ciertos procesos culturales. En palabras de Kurlat Ares:

El desplazamiento de la hegemonía (desde el liberalismo clásico hacia la izquierda) en el campo cultural puso en marcha toda una serie de debates que suponía la existencia de premisas tales como que el intelectual era un agente cultural capaz de promover cambios sociales, que los debates intelectuales y los debates sobre la praxis política conformaban una unidad y que en el campo cultural se decidían las prácticas políticas que darían forma a lo social (54).

Por último, y con respecto a la idea del compromiso, es preciso seńalar que en Latinoamérica no solo se mide en términos sartreanos, sino que al mismo tiempo entran en juego premisas continentales de conciencia sobre la propia situación de colonialismo aún en pleno siglo xx. En este sentido, la consciencia del subdesarrollo viene al introducir en la lucha ideológica de estos intelectuales una filiación antiimperialista. Dice al respecto Ulloa Bustinza:

Frente a la mirada, algo mitificadora, de la realidad latinoamericana que encontramos en los escritores del boom, toma cuerpo una progresiva conciencia ideológica bastante desmitificadora que, partiendo de la asunción del subdesarrollo en América Latina, tiene fe en la transformación de la sociedad a través de la revolución. Su base es el ideario internacionalista e integrador de Simón Bolivar y José Martí, a los que se suman, con el paso del tiempo, los conceptos de Sartre y Brecht respecto a la situación de los intelectuales en tiempos de crisis. Los escritores revolucionarios defenderán el uso de la fuerza en un contexto revolucionario y muchos de ellos alternarán la producción literaria con el activismo político y la lucha de guerrillas (91).

El 'estar situados en su realidad', para los intelectuales latinoamericanos tiene una estrecha relación con la reflexión sobre la propia identidad, con la interpretación de la propia dependencia y con un deseo de emancipación que, intermitentemente, se percibirá unido a una integración continental. Todos estos tópicos han tenido en el continente una especial vinculación con el género ensayístico.

\section{El ensayo en la tradición latinoamericana}

En este sentido, y con respecto al ensayo, es notoria su íntima relación con los procesos identitarios y de conformación de una consciencia tanto nacional como latinoamericana. Miguel Gomes, en su ya clásico Los géneros literarios en Hispanoamérica, llega a considerar al ensayo como uno de los géneros característicos de Hispanoamérica, haciendo la siguiente salvedad: «la originalidad, por supuesto, con respecto a los modelos genológicos de la antigua metrópoli, que por entonces no conocían esta forma con claridad» (218). Es decir: no existía para el siglo XIX en el viejo continente un uso del género lo suficientemente desarrollado como para que sirva de modelo de transferencia cultural hacia la colonia, como sí lo había, en cambio, para la lírica, el drama y la narrativa.

Género que rehúye siempre a los encasillamientos, comparte con nuestro continente esa naturaleza compleja y plural, esa dificultad para definiciones tajantes y cerradas. En Latinoamérica, el ensayo se presenta como discurso textual específico que permite el debate crítico sobre la cultura y las ideologías; y sobre las distintas concepciones que la literatura ha tenido respecto de su función socio-política en nuestro territorio. Al respecto, Aínsa, en su obra Ensayos, sostiene que "(...) el pensamiento americano se expresa a través de este género marcado por la intensa conciencia de la temporalidad histórica: 
elabora diagnósticos socioculturales sobre la identidad nacional y continental»(34).

De este modo, se ofrece como escenario propicio para debates ideológicos en estrecha relación con el ejercicio del periodismo, que a su vez ha generado espacios de sociabilidad intelectual, e influyó en la conformación de "grupos» y "generaciones». Nuevamente en palabras de Aínsa: «El intelectual y la sociedad, el intelectual y la política, la misión y el compromiso forman parte de la reflexión ensayística» en América (48).

El género ensayístico ofrecía algunas características que incidieron en la predilección que los intelectuales demostraron por su forma. Entre estas características, podemos mencionar que el ensayo, en primer lugar, construye el conocimiento desde la asunción de un particular punto de vista del tema tratado que, naturalmente, es subjetivo. La construcción discursiva se observa marcada por una fuerte presencia del enunciador en el texto, el cual se presenta como absolutamente identificado con lo que sostiene. El enunciador no busca sustraerse, sino que, por el contrario, asume su responsabilidad discursiva. Dice Aínsa al respecto:

El ensayista es siempre el núcleo vital de lo tratado, un centro de irradiación germinativa a partir del cual despliega su tema, aunque se disimule en un «nosotros» colectivo o en un «yo» nacional (50).

Por otro lado, la naturaleza dialéctica del ensayo está siempre inserta en un presente de la enunciación (que también confluye en su caracterización de provisional). Tiene, de suyo, un carácter dialogal: un sujeto que construye el conocimiento de manera persuasiva, apelando a un lector en tanto lo hace partícipe de la experiencia que protagoniza al ensayar. Ambos caracteres, el dialógico y el dialectal, son al mismo tiempo distintivos de las letras de nuestro continente, según Gomes: «(...) desde que aparece la noción de una literatura 'propia' de Hispanoamérica la búsqueda de la identidad se efectúa mediante senderos dialógicos, es decir, de discusión e intercambio activo con lo que se reconoce como alteridad» (212).

Por último (y sin pretensión de agotar aquí la caracterización del género), traemos a colación la siguiente observación de una de las principales teorizadoras del ensayo latinoamericano, Liliana Weinberg:

(...) en su carácter de prosa artística mediadora entre otras formas de prosa (ya que su propia organización textual incluye muchas formas discursivas), el ensayo resulta clave como forma de articulación de distintas manifestaciones de la prosa y la literatura de ideas (114).

No resulta extraño de este modo que dicho género haya terminado por representar la discursiva predominante (aunque no excluyente) entre los «intelectuales comprometidos», ya que manifestaba ciertas regularidades y sistemas de relaciones que hacen posible una determinada legitimación de ese mismo discurso.

\section{El ensayo como práctica discursiva del intelectual comprometido}

De lo hasta aquí expuesto, se desprenden algunas conclusiones parciales: en primer lugar, los intelectuales, además de autodefinirse, producen todo un universo discursivo que funciona como legitimador de su propia práctica. En segundo lugar, el ensayo representa, para estos intelectuales comprometidos de nuestro continente en la segunda mitad del siglo $\mathrm{xx}$, una opción en tanto práctica discursiva para tal fin, ya que ofrece

...un sentido de urgencia ideológica más persuasivo que demostrativo, y donde el conocimiento del mundo no se puede separar del proyecto de transformarlo. El ensayo rehúye adoptar un cordial eclecticismo y opta, en general, por una actitud militante, esa 'poderosa carga estética y ética compuesta de acción’ (Aínsa 37).

$\mathrm{Al}$ mismo tiempo, el ensayo ofrece un resultado performativo, en tanto práctica discursiva que busca generar resultados específicos (y extra textuales) en el auditorio a quien se dirige. En tanto práctica discursiva, el lenguaje se presenta como una acción, como una actividad social específica que tiene como fin, para los llamados «intelectuales comprometidos», legitimizar su propia práctica y configurar un universo simbólico que sustente la visión de mundo de la cual se quiere hacer partícipe al lector. En este sentido, pensar la ensayística del intelectual comprometido como práctica discursiva,

implica pensar a los discursos como acontecimientos (en el sentido foucaultiano) que inciden de manera fundamental en la producción y reproducción de la vida social, cultural, histórica (Haidar 144). 
Estas prácticas discursivas polemizaban a favor de la consecución de una legitimación que permitiera a los intelectuales erigirse como autoridades y desempeñar así su función de guías ideológicos de un determinado grupo social; como legitimadores de los bienes simbólicos de la comunidad de la cual forman parte. Es en el género ensayístico donde, en palabras de Miguel Gomes, «(...) el deslinde de lo verbal y lo ideológico se hace inadmisible» (121). Subyace a la elección genólogica que del ensayo hace el intelectual comprometido no solamente una función transitiva cuyo objetivo es transformar el entorno, sino que esta función se hace posible mediante aquello que el crítico denomina "fusión retórica»: «la escritura y el objeto de la escritura se identifican, hasta sugerir que la única solución o la clave de los problemas planteados está en la actividad literaria misma» (219).

\section{La ensayística de Mario Benedetti: hacia la configuración de un macrotexto}

La producción literaria de Mario Benedetti ha suscitado en los diversos críticos que han estudiado su obra una coincidencia respecto determinados aspectos que la caracterizan. Se pueden mencionar como constantes en el análisis de su obra, la observación de su vocación 'comunicante', su compromiso con la realidad y la coherencia de su literatura y su persona. En palabras de Sylvia Lago,

La globalidad de su obra se presenta como un macrotexto de 'secreta armadura', de ajustado equilibro. (...) hoy no se vacila en considerar su producción como una totalidad aurítmica cuyos variados enfoques componen una estructura coherente, un proyecto cultural complejo y sólido de amplio espectro elucidatorio (45).

Ahora bien, saliendo de la globalidad de su obra y centrándonos exclusivamente en el género ensayístico, resulta evidente una gran deuda que hay respecto a su teorización. Este vacío de la crítica se pone de manifiesto sobre todo cuando observamos la utilidad que podría suponer un estudio más profundo sobre el ensayo benedettiano, ya que en dicho abordaje pueden encontrarse las claves de lectura de toda su poética, entendida esta como proyecto cultural determinado. El ensayo, dentro del marco de la totalidad de la obra de Mario Benedetti, funciona muchas veces como una poética explícita y una historia intelectual implícita, en donde puede apreciarse de modo cabal su evolución ideológica. Sobre esto, dice Cunha Giabbai:

Si bien el cimiento ideológico de la vasta obra literaria de Mario Benedetti está formado por ideas políticas, sociales y culturales (...) es en su ensayismo donde las mismas se han sedimentado y formado un corpus definido, sólido y de extraordinario valor (13).

La presencia de ciertas constantes temáticas (la crítica al conformismo en oposición al compromiso, la identidad latinoamericana, el antiimperialismo, el compromiso, el rol del intelectual, la revolución; por mencionar solo las más importantes) como así también una marcada y permanente manera de emprender el hecho literario (la preocupación constante por el lector, el coloquialismo y la comunicabilidad, la preponderancia de una dimensión pragmática de la literatura, entre otras características) hacen que sea posible abordar la ensayística de Mario Benedetti como un macrotexto. Existe una cohesión interna que está dada no solo por las isotopías semánticas que le son propias, sino también porque estos textos se presentan como un conntinum que persiguen un objetivo particular: participar en los debates sobre la actualidad histórica y política (primero de la Patria uruguaya, luego de la Patria Latinoamericana) y reflexionar sobre los problemas de los usos de la literatura y el rol del intelectual. Sus constantes reflexiones sobre la relación entre el contexto político y las prácticas culturales condicionarán toda su práctica estética, pero es precisamente en el ensayo donde dichas reflexiones se textualizan.

$\mathrm{Al}$ mismo tiempo, y siguiendo las categorizaciones ofrecidas por Marc Angenot en La parole pamphlétarie, el macrotexto benedettiano comparte en su configuración una dimensión polémica del discurso, ya que el mismo, en su generalidad, se presenta como persuasivo, doxológico, y supone en su propia estructura un discurso antagonista. Este macrotexto, en tanto discurso agónico, participa en las luchas que, junto con los de su generación, llevará a cabo por el poder simbólico. Centrándose en el lector, persigue una finalidad perlocutiva, en donde las estructuras retóricas se ponen en función de la persuasión que se busca conseguir y, en última instancia, la hegemonía cultural (hablando en función de la 'generación de Marcha') o la contrahegemonía (en tanto intelectual revolucionario) que se persigue.

Esta cohesión interna que el macrotexto benedettiano ofrece está determinada también por su mismo 
carácter ensayístico, ya que dicho género puede abordarse como un espacio discursivo, en el cual, a través del lenguaje, se materializan los diferentes posicionamientos de las luchas por el poder simbólico. En el caso particular del escenario intelectual latinoamericano de la segunda mitad del siglo xx, el ensayo puede ser entendido como una práctica discursiva que se pone al servicio de la consecución de una legitimación que permita a los intelectuales (comprometidos, críticos, revolucionarios) erigirse como autoridades y desempeñar así su función de guías ideológicos de un determinado grupo social; como legitimadores de los bienes simbólicos de la comunidad de la cual forman parte.

En tanto ensayos, podemos considerar que este macrotexto benedettiano, en palabras de Arlandis López, "partiendo de una larga y plural tradición literaria, se ajusta a unos principios organizativos y a unas constantes temáticas y estructurales que los identifican precisamente como tradicionales» (320). No se trata solamente de una continuidad de los objetivos perseguidos, sino también de toda una isotopía temática que entronca con la tradición ensayística hispanoamericana: la identidad, el latinoamericanismo, el rol del intelectual, el antiimperialismo. Hay, a través del tratamiento que la ensayística benedettiana hace de estas temáticas, una interdependencia de sentido que atraviesa todo el macrotexto y, al mismo tiempo, lo configura como tal.

Siguiendo estas consideraciones, el macrotexto benedettiano se presenta como un conjunto articulado en el cual el tono apelativo se conjuga con el compromiso y una particular concepción de la literatura, con el objetivo de persuadir a los lectores sobre la particular visión que el autor ofrece de la realidad literaria y social del contexto en el que se encuentra inserto. Al respecto, es de fundamental importancia destacar que en este macrotexto la producción textual está condicionada por una correspondencia con una praxis cultural y política específica: tanto el ejercicio permanente del periodismo como su participación como embajador cultural en Casa de las Américas, así como también su práctica política revolucionaria son coordenadas vitales que dan a la ensayística benedettiana una especial organicidad y cohesión en tanto práctica discursiva de un intelectual comprometido.

Otra de las características de este macrotexto benedettiano es la sistematicidad que ofrece en tanto ámbito de teorización y reflexión estética de aquellos parámetros literarios que serán experimentados desde la ficcionalidad tanto en la narrativa como en la poética y la dramática. De acuerdo a este punto de vista, la ensayística ofrece una regularidad y una articulación del sistema de ideas respecto de las diferentes consideraciones que el autor va realizando sobre la literatura y su función social. Se puede entonces observar una coherencia respecto de su carácter de poética implícita e, incluso en algunos casos, explícita - como puede notarse en el caso del "tríptico" Montevideanos (cuentos), Poemas de oficina (poesía) y El pais de la cola de paja (ensayo); o la relación El escritor latinoamericano (ensayo) y La casa y el ladrillo (poesía)-.

\section{La función del intelectual y el compromiso en la ensayística de Mario Benedetti}

Como ya se sostuvo en el apartado anterior, el ensayo es para el autor un género en el cual hace explícitos sus posicionamientos éticos, estéticos y políticos. El análisis de estas «declaraciones de principios» incluidas siempre y como una constante en sus ensayos, permite observar una evolución ideológica del autor ${ }^{1}$. Puede verse, como constantes que atraviesan tangencialmente las diferentes etapas de su ensayística, dos características. La primera es una profunda coherencia entre los postulados que hace explícitos en sus ensayos sobre la manera de entender la literatura y el rol del escritor, por una parte; y la puesta en práctica de esas afirmaciones en los otros géneros que aborda, por otra. De este modo, funcionan como ejemplo de lo anteriormente expuesto la identidad en la concepción del hecho literario que subyace a la tríada El país de la cola de paja (ensayo) - Montevideanos (cuento) - Poemas de oficina (poesía); donde el ojo está puesto en la crítica a una sociedad (la uruguaya) cuyos valores habían caído en decadencia y en donde todo parecía estar impregnado por un conformismo y mediocridad que el autor denuncia, de manera explícita, en el ensayo de 1960.

Este acento puesto en lo ético y lo moral que subyace a toda la crítica que el autor realiza a la sociedad montevideana a través de dicho ensayo, nos lleva a la segunda característica: toda la ensayística de

1. La periodización de las diferentes etapas de su producción ensayística tienen como principales antecedentes los trabajos de Luis Paredes e Iván Ulloa Bustinza. Su análisis, que exceden los límites del presente artículo, pertenece a un estudio de mayor alcance: la realización de una tesis doctoral titulada: «La ensayística de Mario Benedetti: práctica discursiva y compromiso intelectual en el campo literario latinoamericano». 
Mario Benedetti estará siempre atravesada por una concepción ética del quehacer ensayístico (y de la literatura en general). De esta manera, su manera de abordar el ensayo coincide con lo que Liliana Weinberg denomina como 'la forma de la moral': "para muchos ensayistas la clave misma del ensayo sigue siendo la cuestión de la moral en el más generoso sentido del término, y que el ensayo no puede pensarse sin un nexo con la ética» (121). Sirva para ilustrar lo anteriormente expuesto la siguiente cita de El escritor latinoamericano...: "Casi por esencia, el arte es muchas veces ambiguo; pues bien, lo que dará un rumbo, un sentido, un color a esa ambigüedad legítima, será la actitud cívica, la actitud como ente social, del artista» (129).

La constante temática del 'compromiso' no es, en última instancia, otra cosa para Benedetti que una deuda ética y moral que cada hombre tiene con su país, con Latinoamérica, con la Revolución; es decir que este 'compromiso' representa un parámetro que también irá evolucionando a lo largo de los años. Así, en El país de la cola de paja se ve una clara influencia sartreana en esta noción de compromiso, como lo explica Nuñez Artola:

Enfrentada al examen de sus costumbres y hábitos, la práctica crítica, entre otras cosas, dará cuenta del oscilante sistema de reglas que hace posible su funcionamiento. Sobre el compromiso existencialista y la acusación a la moral tradicional regida por la razón, Benedetti configura un definido proyecto ético. La práctica crítica obedecerá a una producción sistemática y reflexiva sobre distintos objetos discursivos y sobre la misma práctica (2).

Ahora bien, si de evolución ideológica se trata, dentro de las diferentes etapas de la producción ensayística de Mario Benedetti existe — más allá de diferentes afiliaciones que va realizando el autorun punto de inflexión determinante, y este es el advenimiento de la Revolución Cubana. El contacto del autor con las ideas marxistas será lo que determine el paso de una preocupación social desde siempre presente - aunque mayormente enfocada en el ámbito nacional y el aspecto moral- a una crítica realizada desde un enfoque político, claramente posicionado a nivel ideológico, y con la preocupación sobre el destino ya no del 'paisito', sino del "continente mestizo».

A partir del libro de ensayos denominado Letras del continente mestizo, el compromiso se reclama en términos continentales y políticos, pero sigue siendo el trasfondo de la reflexión sobre el arte poética, siempre en profunda relación para Benedetti, con los fenómenos extraliterarios:

No creo en el compromiso forzado, sin profundidad existencial; ni en la militancia que desvitaliza un tema, ni menos aún en la moraleja edificante que poda la fuerza trágica de un personaje. Pero tampoco creo en el hipotético deslinde, en esa improbable línea divisoria que muchos intelectuales, curándose en salud, prefieren trazar entre la obra literaria y la responsabilidad humana del escritor (19).

Podemos observar en esta cita que hace mención a los 'intelectuales', término que, si bien usará de manera equivalente al de 'escritor', irá utilizando más asiduamente cuanto más se involucre con las ideas revolucionarias, y mientras más se convierta este mismo rol en un tema de principal debate. A partir de Letras del continente mestizo, se verá una marcada preocupación no solo por la definición del intelectual en sí mismo - en cuanto categoría - sino en la dilucidación de los alcances que tiene dicho rol, y cómo debe conjugarse el mismo con el hecho cultural en general y literario en particular. Al mismo tiempo, cabe señalar que ambos términos, escritor e intelectual, aparecen siempre ligados a una primera persona plural que Benedetti utilizará en la mayoría de sus ensayos, y que va alternando con ese yo poético que tanta identidad muestra, a su vez, con el Benedetti de la vida real. De este modo, la primera del plural será utilizada sobre todo para posicionamientos de tipo ideológico; y será equivalente a 'el pueblo' o 'los revolucionarios': "Nosotros ${ }^{2}$ por el contrario creemos que la esencia del pueblo debe llegar a ser sujeto del poder y de la política» (Benedetti, El escritor latinoamericano 140).

Ocurre, entre Letras del continente mestizo y El escritor latinoamericano... un cambio de perspectivas que está relacionado directamente con el vínculo cada vez más estrecho que Benedetti irá forjando con la Revolución Cubana; pero también con el distanciamiento del mismo Sartre después del incidente del caso Padilla y, concretamente, el

2. El subrayado es nuestro. En esta cita, Benedetti opone ese 'nosotros' a un ellos, representado en este caso por Paz y Segovia, a quienes critica duramente por sus declaraciones en torno a la figura del escritor. Sobre este último dice, inmediatamente antes de la cita expuesta, "Hay que pensar entonces que su presunta ideología es un izquierdismo con vocación de derrota. O sea un izquierdismo sin razón de ser» (1974: 140). 
manifiesto de 'los 62'. A partir de entonces, el compromiso para Benedetti ya no se medirá en términos sartreanos, sino más bien marxistas, sobre todo bajo los lineamientos gramscianos, como observamos en esta cita de El escritor latinoamericano y la revolución posible:

O sea que la única forma de que el escritor venza su soledad y supere su frustración o su egoísmo (meros síntomas del subdesarrollo cultural) es que aporte su esfuerzo a la lucha de clases (...) Solo participando de algún modo en la transformación colectiva, adquirirá el escritor su inalienable derecho a sentirse transformado. Gramsci lo ha dicho de una manera impecable, al hablar de la «lucha por una nueva cultura, esto es, por una nueva vida moral (...) (164-165).

En ensayo de 1974, vemos ya una búsqueda intensa por una manera de concebir el rol del intelectual que pueda conciliar el compromiso con la literatura, y con la Revolución. En el proceso de construcción de una literatura revolucionaria, los límites entre el hombre de acción y el hombre intelectual no serán fáciles de establecer. El dilema se establecerá entre los dos extremos indeseables: el realismo socialista y el hermetismo literario — del cual se comenzará a acusar sobre todo a los representantes del boom, los que se refugian en «la palabra, esa nueva cartuja» (1974: 51).

Estas dos prioridades, la literatura y la Revolución, en más de una oportunidad se presentarán como una encrucijada y lo harán derivar en aparentes contradicciones o sucesivas reformulaciones. Un ejemplo de dichas reformulaciones es el caso de su postura sobre la función misma del intelectual y su papel dentro del proceso revolucionario. De este modo, en Letras del continente mestizo el autor sostiene:

El intelectual verdaderamente revolucionario nunca podrá convertirse en un simple amanuense del hombre de acción; y si se convierte, estará en realidad traicionando la revolución, ya que su misión neutral dentro de la misma es ser algo así como su conciencia vigilante, su imaginario intérprete, su crítico proveedor (30).

Sin embargo, algunos años más tarde (y, sobre todo, después de la ruptura ya mencionada que supuso en el campo intelectual el caso Padilla) en El escritor latinoamericano... Benedetti se pronuncia entonces en otro sentido (parafraseando a Fidel y rectificando sus propias palabras):
Continuar tratando de subvertir un orden que entonces sería socialista, significaría sencillamente pasar a militar en la contrarrevolución. Es una regla mínima de coherencia (...). Dentro de la revolución cabe perfectamente la literatura crítica, y sobre todo una actitud crítica, pero siempre dentro de la revolución y no fuera de ella... (75).

El análisis exhaustivo de los ensayos benedettianos, y la confrontación de los mismos respecto de la relación que se establece entre la ideología que en cada uno subyace y la repercusión que la misma tiene en la particular poética de cada etapa, excede ampliamente los límites de este trabajo, pero se enmarcan en un estudio mayor que tiene ese objetivo como una de sus metas.

\section{Conclusiones}

La ensayística benedettiana puede abordarse como un macrotexto en tanto presenta una cohesión que está dada por una dimensión polémica del discurso, ya que puede observarse en ellos un aspecto doxólogico, un aspecto persuasivo y una constante apelación a un contradiscurso.

En tanto género ensayístico, este Macrotexto responde a una clara tradición continental de reflexión sobre la identidad de las naciones y del pueblo latinoamericano, como así también de lucha contra el agente opresor que perpetúa el colonialismo y determina un subdesarrollo cultural y material. Estos tópicos son asumidos desde una voz enunciadora que no busca borrar su huella en el discurso, sino que se asume como un sujeto particular que contribuye a la lucha desde su espacio discursivo por instalar nuevas ideas que, con el devenir de los sucesos latinoamericanos en general y de la vida del autor uruguayo en particular, se volverá también una lucha revolucionaria.

Esta $\pi 0 \lambda \varepsilon \mu 1 \kappa \eta ́$ (polimiké) presente en el Macrotexto benedettiano, este constante combatir con un discurso antagónico, otorga un sentido pragmático a un discurso, y de ahí su abordaje como práctica discursiva. Los ensayos de Mario Benedetti pueden analizarse como un espacio discursivo, en donde, a través del lenguaje, se materializa un posicionamiento específico de las luchas por el poder simbólico. Es posible analizar estos ensayos como una práctica discursiva que se pone al servicio de la consecución de una legitimación que le permita, en tanto intelectual (primero desde la «generación de 
Marcha» y con un horizonte nacional, luego desde las filas revolucionarias y con un horizonte ya continental) erigirse como autoridad y desempeñar así su función de guía ideológicos de un determinado grupo social; como legitimador de los bienes simbólicos de la comunidad de la cual forma parte.

\section{Bibliografía}

Aínsa, Fernando. Ensayos. Montevideo: Trilce, 2014.

Altamirano, Carlos. Intelectuales: notas de investigación sobre una cultura inquieta. Buenos Aires: Siglo Veintiuno editores, 2013.

Angenot, Marc. La parole pamphlétarie. Paris: Payot, 1982.

Angenot, Marc. El discurso social: los limites históricos de lo pensable y lo decible. Buenos Aires: Siglo veintiuno editores, 2010.

Arlandis López, Sergio (2016), «El macrotexto poético: claves para su determinación metodológica», Mitologias hoy, 14, (2016): 317-335. Disponible en: http://revistes.uab.cat/mitologias/article/view/ v14-lopez

Bauman, Zygmunt. Legisladores e intérpretes. Buenos Aires: Universidad Nacional de Quilmes, 1997.

Benedetti, Mario. Letras del continente mestizo. Montevideo: Arca, 1967.

Benedetti, Mario. El pais de la cola de paja. Montevideo: Bolsilibros Arca, 1968.

Benedetti, Mario. El escritor latinoamericano y la revolución posible. Buenos Aires: Ed. Alfa Argentina, 1974.

Blanco Blanco, Elvira. La creación de un imaginario: La generación Literaria del 45 en el Uruguay. Montevideo: Tradinco, 2007.

Da Cunha Giabbai, Gloria. El exilio, realidad y ficción. Montevideo: Arca, 1992.
Gilman, Claudia. Entre la pluma y el fusil: debates y dilemas del escritor revolucionario en América Latina., Buenos Aires: Siglo veintiuno editores, 2012.

Gomes, Miguel. Los géneros literarios en Hispanoamérica: teoría e historia. Navarra: EUNSA, 1999.

HaIDAR, Julieta. «Las materialidades discursivas: un problema interdisciplinario», Alfa, 36, (1992): 139-147. Disponible en: http://seer.fclar.unesp.br/alfa/article/ viewFile/3914/3595.

Kurlat Ares, Silvia. Por una intelectualidad sin episteme: el devenir de la literatura argenitna (1974-1989). Buenos Aires: Corregidor, 2006.

Lago, Sylvia. Mario Benedetti: cincuenta años de creación. Montevideo: Universidad de la República, 1996.

Larre Borges, Ana Inés (1999). "Lector y fábula: la opción ética-estética en la obra de Mario Benedetti». Alemany Bay, Carmen (ed.). Mario Benedetti: inventario cómplice. Disponible en: http://www. cervantesvirtual.com/obra-visor/mario-benedettiinventario-complice-0/html/ff1470c0-82b1-11dfacc7-002185ce6064_74.htm\#I_8_.

Nuñez Artola, María Gracia. Un paradigma de propuesta crítica: El país de la cola de paja. Espéculo. Revista de estudios literarios. Universidad Complutense de Madrid. «N.p» «n.d». http://www.ucm.es/info/especulo/ numero26/colapaja.html. Consultado el 29 noviembre 2018.

SARTre, Jean Paul. ¿Qué es la literatura? Buenos Aires: Losada, 2008.

Ulloa Bustinza, Iván. Evolución ideológico-literaria en la obra poética de Mario Benedetti. (Tesis doctoral inédita) Universidad de Vigo, España, 2008. Disponible en: http://www.red-redial.net/referenciabibliografica-30823.html

Weinberg, Liliana (2007) «El ensayo latinoamericano entre la forma de la moral y la moral de la forma», Cuadernos del CILHA. Dossier: el Ensayo latinoamericano. Mendoza: Universidad Nacional de Cuyo, 2007. 